\title{
Anterior cervical discectomy and fusion: Comparison of titanium and polyetheretherketone cages
}

Mario Cabraja*, Soner Oezdemir, Daniel Koeppen and Stefan Kroppenstedt

\begin{abstract}
Background: Titanium (TTN) cages have a higher modulus of elasticity when compared with polyetheretherketone (PEEK) cages. This suggests that TTN-cages could show more frequent cage subsidence after anterior cervical discectomy and fusion (ACDF) and therefore might lead to a higher loss of correction. We compared the long term results of stand-alone PEEK- and TTN-cages in a comparable patient collective that was operated under identical operative settings.
\end{abstract}

Methods: From 2002 to 2007154 patients underwent single-level ACDF for degenerative disc disease (DDD). Clinical and radiological outcome were assessed in 86 eligible patients after a mean of 28.4 months. 44 patients received a TTN- and 42 patients a PEEK-cage.

Results: Solid arthrodesis was found in $93.2 \%$ of the TTN-group and $88.1 \%$ of the PEEK-group. Cage subsidence was observed in $20.5 \%$ of the $T \mathrm{~N}$ - and $14.3 \%$ of the PEEK-group. A significant segmental lordotic correction was achieved by both cage-types. Even though a loss of correction was found at the last follow-up in both groups, it did not reach the level of statistical significance. Statistical analysis of these results revealed no differences between the TTN- and PEEK-group.

When assessed with the neck disability index (NDI), the visual analogue scale (VAS) of neck and arm pain and Odom's criteria the clinical data showed no significant differences between the groups.

Conclusions: Clinical and radiological outcomes of ACDF with TTN- or PEEK-cages do not appear to be influenced by the chosen synthetic graft. The modulus of elasticity represents only one of many physical properties of a cage. Design, shape, size, surface architecture of a cage as well as bone density, endplate preparation and applied distraction during surgery need to be considered as further important factors.

\section{Background}

Cervical titanium (TTN) and polyetheretherketone (PEEK) cages for intervertebral disc space reconstruction are both accepted grafts for anterior cervical discectomy and fusion (ACDF) [1-7].

TTN-cages have been criticized to produce an inferior clinical outcome compared with bone grafts due to a higher elasticity modulus, which could result in subsidence [8]. Nevertheless, due to structural properties TTN implants are likely to provide a good osseointegration [9] and several clinical studies demonstrate successful results after implantation of TTN-cages [10-13].

\footnotetext{
* Correspondence: mario.cabraja@charite.de

Department of Neurosurgery, Charité-Universitätsmedizin Berlin, Hindenburgdamm 20, Berlin 12200, Germany
}

PEEK-cages have a modulus of elasticity closely resembling that of cortical bone, which might lead to advantages in load sharing and stress distribution. This might result in a lower subsidence rate with less loss of segmental correction and potentially higher fusion rate [14-16].

A direct comparison of cervical TTN- and PEEK-cages in a clinical setting is very rarely found in the literature [16-19], and even less studies consequently compare the radiological results $[16,18]$. The latter studies showed the PEEK-implants being superior in maintaining cervical interspace height and achieving radiographic fusion $[16,18]$, even suggesting to cease the application of TTN-cages in cervical spine surgery [16].

The aim of the present study was to evaluate the fusion of the operated segment and to examine the rate of

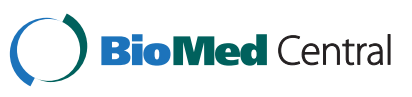


cage subsidence as well as clinical outcome in two comparable patient collectives.

\section{Methods}

\section{Patient cohort}

From 2002 to 2007 according to our records a total of 252 patients underwent ACDF. For better comparison we have excluded patients with multilevel surgery, previous or subsequent surgery of the cervical spine, cage fillings with allo-, autograft or bone substitutes, additional plating for single-level ACDF or patients suffering from an infection or traumatic spinal cord injury. Patients that did not appear to at least one-year follow-up were excluded as well (see Figure 1).

The study conforms to the Helsinki Declaration, and to local legislation. By protecting the patients' anonymity, approval of our institutional ethics committee is not required for this retrospective study.

The included patients experienced radiculopathy and neck pain as main symptoms. 16 patients suffered from a myelopathy (see Table 1). All of the patients underwent conservative treatment unsuccessfully.

\section{Surgery}

ACDF was performed in supine position by a transverse skin incision from the right side after induction of general anaesthesia. After removal of the disc, preparation of the endplates with a rongeur and decompression of the nerval structures the intervertebral space was filled with an empty stand-alone synthetic cage under anterior distraction. Great care was taken to remove the cartilaginous tissue, but preserve intact endplates. No drill was used for the preparation of the endplates. The cage was placed close to the anterior margin of the spine to achieve a segmental lordosis.

The patients received either a CeSpace ${ }^{\circledR}$ Titan cage with Plasmapore ${ }^{\circledR}$ coating or a CeSpace ${ }^{\circledR}$ PEEK cage (B Braun Aesculap, Tuttlingen, Germany) (see Figure 2). Both cage types were applied in sizes from $4-7 \mathrm{~mm}$ in height with a diameter of $16 \mathrm{~mm}$, depth of $13.5 \mathrm{~mm}$ and an angle of $5^{\circ}$. The choice of cage size depended mainly on the height of the adjacent intervertebral disc space and the sagittal profile. The cage was chosen to be at least $1 \mathrm{~mm}$ higher than the affected disc, but was not supposed to exceed a normal adjacent level disc substantially. The exact disc height of the normal adjacent level was not measured pre- or intraoperatively, but was estimated by cage trials and lateral fluoroscopy during surgery. The choice of the cage material depended on the surgeon's personal preference.

After surgery, all patients were treated by the same protocol, which consisted of physical rest for 6 weeks and then physical therapy. A cervical collar was not applied.

\section{Clinical and radiological evaluation}

Follow-up examinations were performed on an outpatient basis in our department. Neck and arm pain were measured using the Visual Analogue Scale (VAS); functionality was assessed with help of the Neck Disability Index (NDI). Overall clinical outcome was rated using Odom's criteria.

Radiographic examinations included pre- and postoperative plain and functional radiography. Radiological analysis involved the measurement of various angles: Cervical lordosis was measured between $\mathrm{C} 2$ and $\mathrm{C} 7$ according to Cobb in neutral position as well as in extension and flexion. The segmental angles of the operated vertebral levels were measured in neutral position as well as in extension and flexion. Additionally, the preoperative anterior and posterior disc height of the operated and the adjacent cranial level was measured. At the last follow-up the occurrence of anterior and posterior bone bridging as well as cage subsidence $(\geq 2 \mathrm{~mm})$ [20] were assessed. Solid arthrodesis was rated according to the following accepted criteria $[1,5,13,21]$ : The operated segment was rated as a solid arthrodesis, if movement of less than $2^{\circ}$ was measured, and by the absence of motion between the spinous processes on lateral flexion-extension radiographs. Movement of $\geq 2^{\circ}$ on flexion/extension radiographs was regarded as a pseudarthrosis $[2,5]$.

Measurements were done on digital radiographs using integrated software to measure angles and distances up to the accuracy of $0.1^{\circ}$ and $0.01 \mathrm{~mm}$, respectively (Centricity Enterprise Web, General Electric Medical Systems, Chalfont St Giles, United Kingdom). The values were expressed as mean with standard deviation. To validate the assessed data the measurements were performed independently by two examiners. Furthermore, the measurement of the depth of the used cages $(13.5 \mathrm{~mm})$ in lateral radiographs served to validate the measurements.

\section{Statistical analysis}

The statistical evaluation was performed using PASW Statistics 18, Version 18.0.0 (SPSS Inc.). Statistical analysis of ASD and gender was performed by Pearson's chi-square test. The clinical and radiological data were analysed by the Mann-Whitney-U-test, Chi-square-test and the Student's t-test. A p-value $<0.05$ was deemed as statistically significant.

\section{Results}

86 of 101 eligible patients (54 men and 32 women) were evaluated. The patients' age at time of surgery ranged from 32 to 74 years, with a mean of 54.3 years. The patients of the PEEK-group were significantly older than the patients of the TTN-group $(p=0.030)$. The followup period ranged from 12 to 60 months (mean: 28.4 months) (see Table 1). 


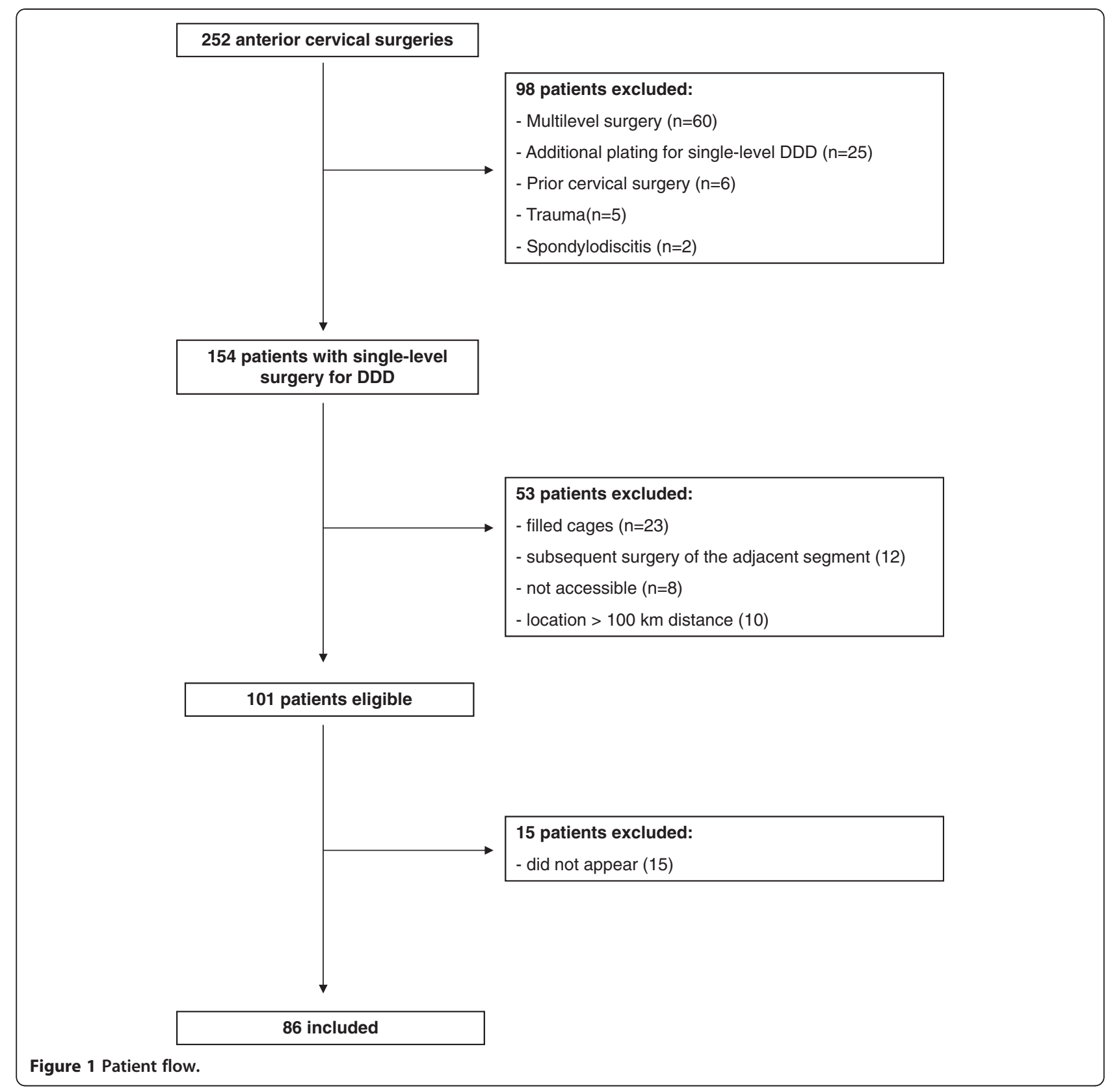

\section{Surgery}

ACDF was performed in 7 cases at $\mathrm{C} 3 / 4$, in 17 cases at $\mathrm{C} 4 / 5$, in 43 cases at $\mathrm{C} 5 / 6$ and in 19 cases at $\mathrm{C} 6 / 7$. The operation time ranged from 56 to 150 minutes, with a mean of 84.4 minutes. The $5 \mathrm{~mm}$ cage was the most frequently chosen implant in both groups. All of these parameters were evenly distributed between the groups (see Table 2). Intra- or postoperative graft dislocation did not occur.

\section{Fusion}

A solid arthdodesis was found in $93.2 \%$ of cases in the TTN-group and $88.1 \%$ of the PEEK-group $(\mathrm{p}=0.417)$ according to our criteria. Bone formation was seen in $79.6 \%$ of the TTN-group, and in $61.9 \%$ of the PEEKgroup ( $\mathrm{p}=0.032)$ (see Figure 3$)$.

The rate of pseudarthrosis was $6.8 \%$ in the TTN- and $11.9 \%$ in the PEEK-group, but allowed no appropriate statistical comparison due to the small number of cases (see Table 3 and Figure 4).

\section{Cage subsidence}

A cage subsidence of at least $2 \mathrm{~mm}$ was detected in $20.5 \%$ of the TTN-group and $14.3 \%$ of the PEEK-group, but did not differ significantly between the groups $(\mathrm{p}=0.451)$ (see Table 3$)$. The amount of cage subsidence 
Table 1 Demographic and clinical data of the patients

\begin{tabular}{llll}
\hline Variable & TTN $(\mathbf{n}=\mathbf{4 4})$ & $\begin{array}{l}\text { PEEK } \\
(\mathbf{n = 4 2})\end{array}$ & p-value \\
\hline Age at surgery (years) & $51.09 \pm 8.88$ & $57.64 \pm 11.10$ & $\underline{0.030}$ \\
\hline Gender & & & 0.768 \\
\hline Male & 26 & 28 & \\
\hline Female & 18 & 14 & \\
\hline Smoker & & & 0.400 \\
\hline Yes & 27 & 22 & \\
\hline No & 17 & 20 & \\
\hline Follow-up (months) & $30.568 \pm 14.32$ & $26.1 \pm 9.97$ & 0.096 \\
\hline Radiculopathy & 36 & 34 & 0.796 \\
\hline Myelopathy & 8 & 8 & 0.918 \\
\hline
\end{tabular}

ranged from $2.02 \mathrm{~mm}$ to $3.88 \mathrm{~mm}$ and did not differ significantly between the groups as well $(\mathrm{p}=0.601) .73 .3 \%$ of cage subsidence was found in the anterior part and $26.7 \%$ in the posterior part without differences between the groups (see Table 3 and Figure 5). Cage subsidence was not affected by cage-size or disc height, ratio of preoperative disc height and cage-size, smoking behaviour or age of the patient $(\mathrm{p}>0.117)$. The interobserver error was $0.11 \mathrm{~mm}$ assessing the amount of cage subsidence and did not affect statistical analysis.

The preoperative disc height of the operated segment in the TTN-group measured $3.71 \pm 1.38 \mathrm{~mm}$ anterior and $3.10 \pm 1.15 \mathrm{~mm}$ posterior. The disc height of the operated segment in the PEEK-group was $3.98 \pm 1.25 \mathrm{~mm}$ anterior and $2.79 \pm 1.14 \mathrm{~mm}$ posterior. Both groups did not differ ( $p>0.211)$. The disc height of the operated level was
Table 2 Surgical Data

\begin{tabular}{llll}
\hline Variable & TTN $(\mathbf{n}=\mathbf{4 4 )}$ & $\begin{array}{l}\text { PEEK } \\
(\mathbf{n}=\mathbf{4 2})\end{array}$ & p-value \\
\hline Operated Segment & & & 0.077 \\
\hline C 3-4 & 1 & 6 & \\
\hline C 4-5 & 7 & 10 & \\
\hline C 5-6 & 23 & 20 & \\
\hline C 6-7 & 13 & 6 & \\
\hline Operation time (min) & $91.91 \pm 16.70$ & $84.44 \pm 19.99$ & \\
\hline Cage size & & & \\
\hline 4 mm & 6 & 3 & \\
\hline 5 mm & 22 & 21 & 0.649 \\
\hline 6 mm & 14 & 14 & \\
\hline 7 mm & 2 & 4 & \\
\hline Average Cage size & $5.27 \pm 0.76$ & $5.45 \pm 0.77$ & \\
\hline
\end{tabular}

significantly reduced compared to the adjacent cranial level in both groups $(\mathrm{p}<0.009)$.

The interobserver error was $0.30 \mathrm{~mm}$ and $0.41 \mathrm{~mm}$ assessing disc height of the operated and adjacent level, respectively, and almost reached the level of statistical significance between the examiners $(p>0.07)$. Since the validity of disc height measurements was inferior to the measurements of the angles, the achievement and loss of correction was assessed by comparison of cervical and segmental angles.

\section{Segmental and cervical lordosis}

A substantial correction of segmental lordosis could be observed in both groups $(\mathrm{p}=0.0001)$. At the last followup a significant loss of correction could be found in both

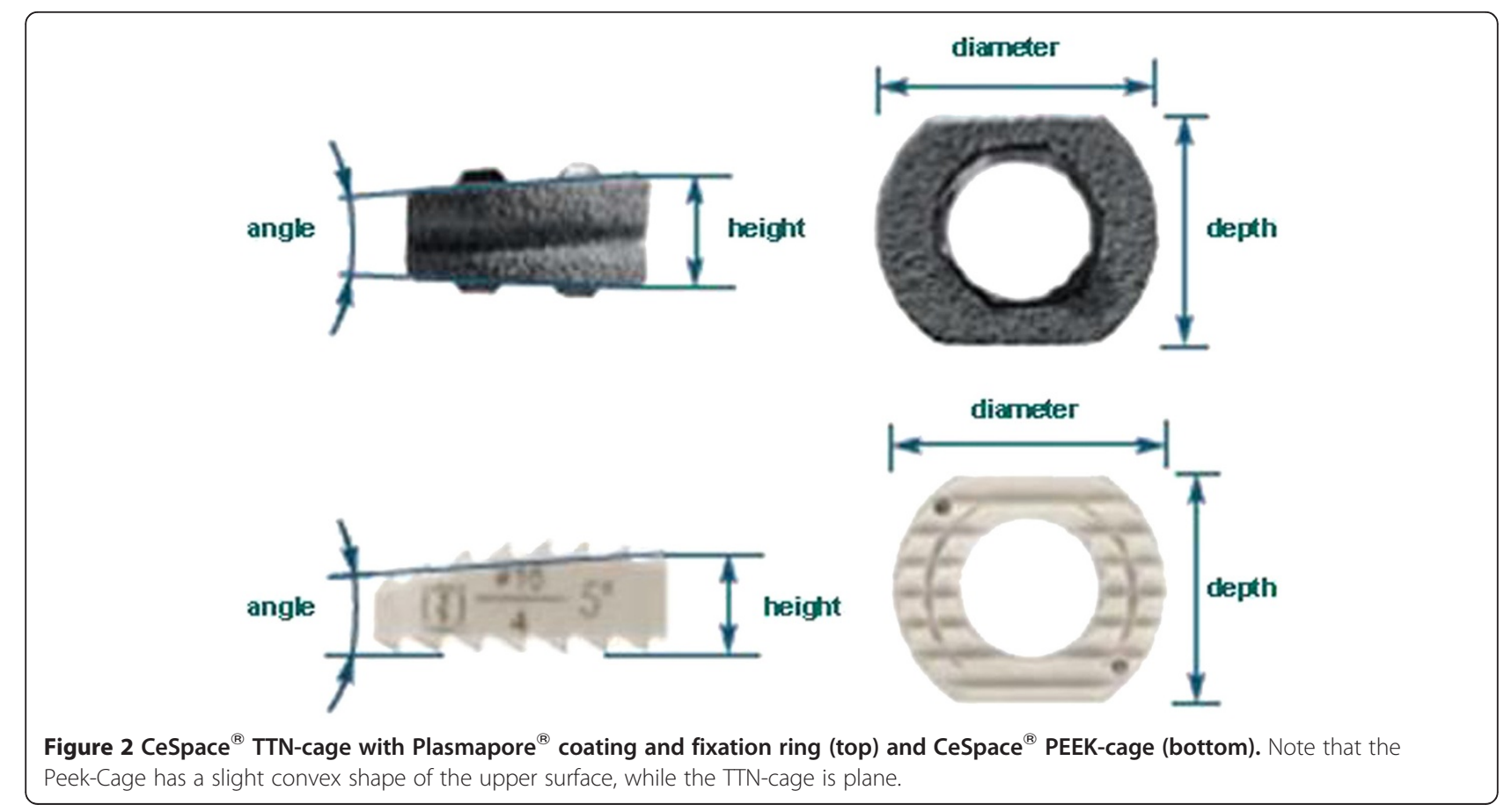




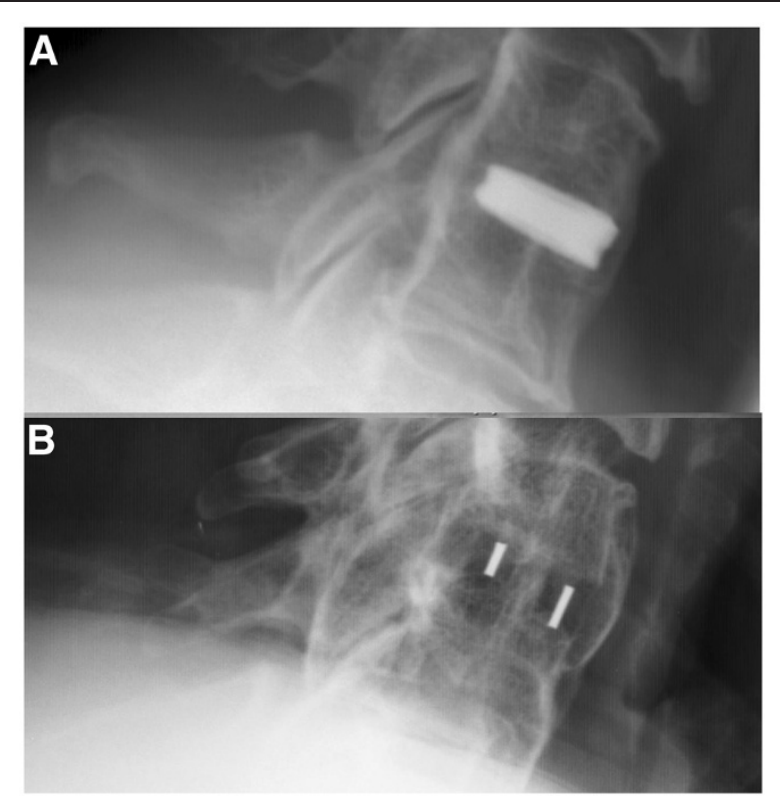

Figure 3 Bone formation could be seen in the TTN-group (A) and PEEK-group (B).

groups $(\mathrm{p}<0.020)$. Nonetheless, compared with the preoperative segmental angle a significant lordotic angulation could be maintained at the final follow-up $(\mathrm{p}<0.031)$. There was no difference between both groups.

The preoperative cervical lordosis was substantially reduced in both groups (see Table 4B). The preoperative comparison of lordotic curvature showed a decreased lordosis in the TTN-group $(\mathrm{p}=0.05)$. A substantial correction of the cervical lordosis could be found in both groups after surgery $(\mathrm{p}<0.048)$. In the TTN-group an overall correction of $3.3^{\circ}$ was achieved (see Table 4A and 4B). A loss of cervical correction was observed in both groups, especially in the PEEK group $\left(4.35^{\circ}\right)$, but did not

Table 3 Arthrodesis, pseudarthrosis and cage-subsidence with total number and percentage

\begin{tabular}{llll}
\hline Variable & TTN $(\mathbf{n}=\mathbf{4 4 )}$ & $\begin{array}{l}\text { PEEK } \\
(\mathbf{n}=\mathbf{4 2})\end{array}$ & p-value \\
\hline Arthrodesis $\underline{\text { n }]}$ & $41(93.18 \%)$ & $37(88.1 \%)$ & 0.417 \\
\hline (Segment ROM $\left.<2^{\circ}\right)$ & & & \\
\hline Pseudarthrosis & $3(6.8 \%)$ & $5(11.9 \%)$ & \\
\hline (Segment ROM $\left.\geq 2^{\circ}\right)$ & & & \\
\hline Bone Bridging & $\mathbf{3 5 ( 7 9 . 5 5 \% )}$ & $\mathbf{2 6 ( 6 1 . 9 \% )}$ & $\underline{0.032}$ \\
\hline Anterior & $32(72.7 \%)$ & $23(54.76 \%)$ & 0.053 \\
\hline Posterior & $28(63.6 \%)$ & $17(40.48 \%)$ & $\underline{0.031}$ \\
\hline Cage-Subsidence & $9(20.45 \%)$ & $6(14.28 \%)$ & 0.451 \\
\hline Cage subsidence & $3.07 \pm 0.33$ & $2.94 \pm 0.64$ & 0.601 \\
\hline [mm] mean \pm SEM & & & \\
\hline
\end{tabular}

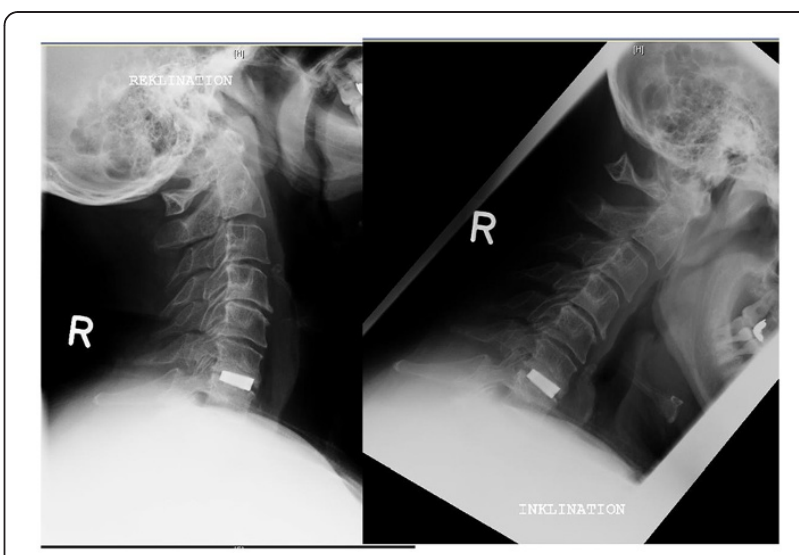

Figure 4 55-years old patient with a pseudarthrosis 3 years after surgery. The motion of the operated segment can be clearly seen by observing the movement of the spinous processes in the lateral functional $\mathrm{x}$-rays.

reach the level of statistical significance $(\mathrm{p}=0.061$ in the PEEK- and $\mathrm{p}=0.294$ in the TTN-group).

The interobserver error was $0.31^{\circ}$ and $0.27^{\circ}$ assessing cervical and segmental lordosis, respectively, and did not affect statistical analysis.

\section{Clinical outcome}

$75 \%(n=33)$ of the TTN-group and $64.3 \%(n=27)$ of the PEEK-group rated an excellent or good outcome $(p=0.395)$. The analysis of the clinical data did not show any significant differences in the two groups as assessed by NDI $(p=0.940)$, VAS $(p>0.460$ for arm and neck pain) and Odom's criteria $(\mathrm{p}=0.229)$ (see Table 5).

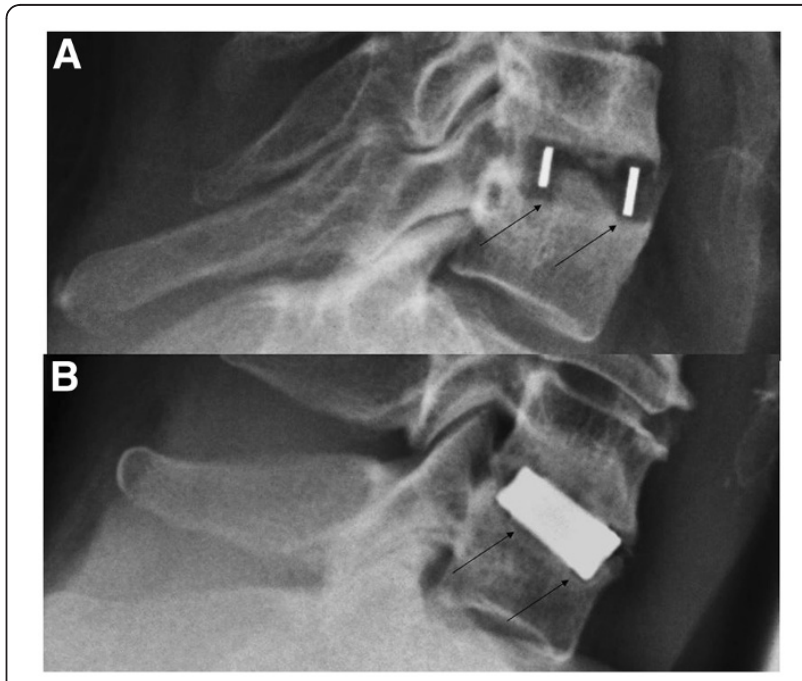

Figure 5 Subsidence of a PEEK-cage into the posterior part of the inferior endplate $(A)$ and subsidence of a TTN-cage into the anterior part of the inferior endplate (B). A radiolucent gap can be seen in both cases around the cage (arrows). 
Table 4 Segmental (A) and cervical lordosis (B)

\begin{tabular}{|c|c|c|c|}
\hline \multicolumn{4}{|c|}{ A) Segmental Lordosis (plain $\left[^{\circ}\right]$ mean \pm SEM) } \\
\hline Variable & $\operatorname{TTN}(n=44)$ & $\begin{array}{l}\text { PEEK } \\
(n=42)\end{array}$ & p-value \\
\hline \multicolumn{4}{|c|}{ Operated Segment $\left[^{\circ}\right]$} \\
\hline Pre-OP & $2.71 \pm 4.68$ & $4.43 \pm 3.37$ & 0.054 \\
\hline Post-OP & $5.49 \pm 3.85^{* *}$ & $6.48 \pm 3.67^{* *}$ & 0.223 \\
\hline Final & $4.06 \pm 3.65^{* *}$ & $5.51 \pm 4.13^{* *}$ & 0.075 \\
\hline \multicolumn{4}{|c|}{ B) Cervical Lordosis (plain $\left[{ }^{\circ}\right]$ mean \pm SEM) } \\
\hline Variable & $\operatorname{TTN}(n=44)$ & $\begin{array}{l}\text { PEEK } \\
(n=42)\end{array}$ & p-value \\
\hline \multicolumn{4}{|l|}{ C2-7 [º] } \\
\hline Pre-OP & $10.750 \pm 14.44$ & $16.31 \pm 11.18$ & $\underline{0.050}$ \\
\hline Post-OP & $14.034 \pm 12.44^{*}$ & $17.64 \pm 9.96^{*}$ & 0.143 \\
\hline Final & $13.140 \pm 12.71$ & $13.29 \pm 7.06$ & 0.288 \\
\hline
\end{tabular}

Clinical outcome was not affected by cage subsidence $(p>0.211)$ or presence of bone formation $(p>0.410)$.

\section{Discussion}

We present a retrospective study comparing patients after ACDF with either stand-alone TTN- or PEEKcages. No differences in clinical outcome could be found between the two groups. Radiological comparison revealed no differences regarding the rate of solid arthrodesis or cage subsidence. A significant segmental lordotic correction could be achieved by both cage-types.

Table 5 Clinical outcome of both groups assessed by the neck disability index (NDI), visual analogue scale (VAS) and Odom's criteria

\begin{tabular}{llll}
\hline Variable & TTN $(\mathbf{n}=\mathbf{4 4})$ & $\begin{array}{l}\text { PEEK } \\
(\mathbf{n = 4 2})\end{array}$ & p-value \\
\hline Final neck VAS-pain & $33.01 \pm 19.48$ & $36.333 \pm 21.28$ & 0.460 \\
\hline$(0-100 \mathrm{~mm})$ & & & \\
\hline Final arm VAS & $23.70 \pm 23.78$ & $25.76 \pm 26.74$ & 0.759 \\
\hline$(0-100 \mathrm{~mm})$ & & & \\
\hline Final NDI & $16.886 \pm 10.24$ & $17.047 \pm 9.61$ & 0.940 \\
\hline Odom's Criteria & & & 0.229 \\
\hline Excellent & 8 & 5 & \\
\hline Good & 25 & 22 & \\
\hline Fair & 9 & 12 & \\
\hline Poor & 2 & 3 & \\
\hline Success of surgery & $33(75 \%)$ & $27(64.3 \%)$ & \\
\hline (=excellent + good) & & & \\
\hline
\end{tabular}

\section{PEEK versus Titanium}

The overall rate of cage subsidence was $17.4 \%$ in both of the groups. The loss of segmental correction in all of our patients at the last follow-up could be regarded as a consequence of cage subsidence as well, but it is of note that we defined a substantial subsidence as a minimum of $2 \mathrm{~mm}$ in lateral radiographs [20].

The incidence of cage subsidence appeared not to be affected by the differences in modulus of material elasticity as has been assumed by some authors $[16,18]$. Niu et al. used cages of different sizes in the compared TTN- and PEEK-groups, although the pre-operative disc height of both groups was comparable. The PEEK-group received cages not bigger than $6 \mathrm{~mm}$, while the TTN-group received cages of no less than $7 \mathrm{~mm}$ and $8 \mathrm{~mm}$ in $86 \%$ of the operated segments and even received $9 \mathrm{~mm}$ cages in 5 operated levels [18]. The application of cages of a substantial size may result in an increased stress of the endplates and thus increased risk of subsidence [22-24]. In the cited study solely the measurement of disc height revealed the loss of correction that led to the conclusion that TTNcages tend to a higher loss of correction. It is not conclusively discussed, why the segmental angulation did not change accordingly to the reduction of the disc height. In our study we observed that the validity of disc height measurement is inferior to the measurement of the Cobb angle of the cervical spine. Furthermore, in the mentioned study the PEEK-cages were filled with cancellous allograft bone, while the TTN-cages were filled with local bone and calcium phosphate bone extender, which may result in different radiological outcomes due to different osteogenic properties. The study of Chou and colleagues favoured PEEK over TTN, but examined only 9 patients in the PEEK-group [16]. Therefore, the statement that PEEKcages are superior to TTN-cages in maintaining interspace height and achieving fusion is not entirely conclusive.

Both cage-types offer certain advantages in spine surgery. TTN-implants likely provide a good osseointegration [9]. Furthermore, their surface structure appears to be comparably resistent to microbial adhesion, although of course many factors affect the incidence of infection [25,26].

The PEEK's modulus of elasticity is close to that of cortical bone and its radiolucency allows for a more accurate assessment of osseous fusion on plain radiographs. It does not compromise MRI-examinations, which is of particular interest in follow-up examinations of patients suffering from myelopathy and neoplastic diseases $[27,28]$.

\section{Cage subsidence}

When comparing PEEK- with TTN-cages the occurrence of TTN-cage subsidence is believed to be related to the higher modulus of elasticity $[16,18]$, but comparison of 
cages of the same material reveals a multifactorial genesis of cage subsidence [20,29,30].

The patients in our PEEK-group were significantly older than in the TTN-group. This could be a random effect, but could also reflect the intuitive reaction of the surgeon towards potentially weaker bone substance in elder patients and consecutive choice of a cage-material with a more favourable modulus of elasticity. Also older patients can be expected to have weaker bone and therefore a potentially higher rate of subsidence. This phenomenon is a potential bias that possibly could have favoured the TTN group. A subsidence of TTN-cages is observed in 13 to $45 \%$ of cases in larger series [10,20]. The reported rate of PEEK-cage subsidence varies from 11 to $18 \%[17,24,31]$. This shows that even the PEEK's favourable modulus of elasticity does not prevent a cage subsidence. The different rate of cage subsidence in various studies dealing with synthetic cages might be also due to different criteria ( 1 or $2 \mathrm{~mm}$ ) and measurement methods $[10,20,24]$. High resolution digital radiographs and digital measurement tools enable a more precise analysis of various conditions in the spine.

The distance of the implant from the anterior rim, a big cage size, small contact area of endplates and cage or overdistraction with subsequently increased stress of the endplates are possible explanations for a cage subsidence $[10,20,22-24,32]$. Our cages had an identical surface area and were placed close to the anterior rim. The ratio of cage size and disc height was no influencing factor on cage subsidence.

Bone quality, graft placement, force, shape of the implant and preparation of the endplates are further major factors that influence cage subsidence $[20,29,30]$.

Revision surgery in case of cage subsidence without clinical symptoms was deemed unnecessary in our series. This goes conform with other studies $[10,24,31]$.

\section{Cervical profile and disc height}

The mean cervical lordosis of our patients measured around $13^{\circ}$ and is comparable with patients suffering from DDD [12,33,34]. It reflects an already substantial loss of lordosis that normally is about $34^{\circ}$ [35]. We managed to improve the cervical lordosis, but still did not achieve nearly normal alignment, which is hardly possible by a monosegmental approach. Furthermore, it is reported that patients may develop a kyphotic angulation at the levels above surgery [34] and subsequent loss of a transient lordotic overall correction. The loss of correction in our PEEK-group does not reach the level of significance, but is notable and could be explained by a disease progression and loss of muscle strength of the older patient collective.

Many authors determine the disc height to measure the achievement and loss of correction [16,36], but the shape of cervical vertebral bodies is, in contrast to the thoracal spine, not consistently rectangular. The concavity of the cervical disc space and the common presence of osteophytes in DDD can compromise the validity of the measurement. Our interobserver error determining disc height was higher than for the measurement of angles, thus we used the measurement of the Cobb angle to determine the achievement and loss of correction $[11,12,33,34]$.

\section{Bone formation}

The higher rate of bone formation in our TTN-group could be explained by three factors: 1 . The patients were younger and could possibly muster larger osteogenic abilities. 2. The Plasmapore ${ }^{\circledR}$ coating of the TTN-cages enlarges the surface and might increase osteoconductive properties compared to the PEEK-cage. 3. Cage subsidence and subsequent exposure of cancellous bone inside the cage might promote fusion in certain cases [31].

The fusion rate of empty TTN-cages is reported to reach even $100 \%$ [13] and exceeds the fusion rate of empty PEEK-cages that is reported to be $72 \%$ [31]. One possible theory claims that fusion of empty cages may occur as the result of endplate failure and subsequent filling of a cage by fracture fragments. In this case the elastic mode of PEEK might prove to be disadvantageous for some patients according to the authors [31]. Nonetheless, it must be considered that fusion is not mandatory for a clinical success, and a loss of disc height and a potential segmental kyphosis might result from a cage subsidence. The comparatively little number of bone formation in our study may relate to the choice of diagnostic means and criteria to asses bony fusion. Assessing bone formation within the cages [31] was no criterion in our PEEK-group. This would have compromised a proper comparison with the TTN-group on lateral radiographs. Also even the PEEK-cages are not entirely radiolucent to allow a certain assessment of bone within the cages. For these reasons only the presence of anterior or posterior bone formation was rated.

The absence of segmental movement was our main criterion to rate a segment as a solid arthrodesis or pseudarthrosis. While in many studies bony union of the operated segment is regarded as the main criterion for a stable fusion $[37,38]$, the study of functional flexionextension radiographs and the position of the spinous processes can reveal motion nonetheless [39] or show a stable segmental status despite the lack of osseous trabeculation [33]. The absence of bony fusion can occur with absence of motion even for a long-term period, which is therefore accepted as a successful criterion for fusion in lateral radiographs $[1,2,5,13,21,33]$. Nonetheless, we preferred the term solid arthrodesis instead of fusion to describe the absence of motion. The comparison of our 
patients with and without bone formation revealed no clinical difference as well [31]. A CT-scan would have allowed a more precise statement of bony ingrowth, but was not performed routinely in our series to avoid an unnecessary radiation exposure.

\section{Surgery and study design}

The surgeries were performed by three neurosurgeons in identical surgical technique in the same neurosurgical department. Nonetheless, this represents a potential bias of the study. The retrospective study design represents the major limitation of the study. The range of follow-up examinations provides a larger degree of interpretation compared to prospective studies with fixed follow-up appointments for all included patients. Preclinical data are limitedly available, and the only clinical outcome measurement is Odom's criteria. The clinical comparison of patients suffering from myelopathy and radiculopathy is difficult, but we have focused on the radiological results of our study, particularly the rate of cage subsidence.

Postoperative external immobilization is often required when stand-alone devices are used. However, we did not observe any case of cage extrusion in our study population. This may be due to the surface structure of the cages, which either feature teeth (PEEK) or are coated with Plasmapore ${ }^{\circledR}$ and use a fixation ring (TTN). Some surgeons advocate rigid internal fixation and cervical immobilization postoperatively to prevent graft migration and nonunion and to enhance fusion $[40,41]$. The outcomes of rigid plate fixation have been equivocal to surgery without internal fixation in some studies [42-44]. In degenerative spondylosis the application of an internal fixation or a collar does not seem to influence the clinical or radiological outcome in a negative manner [45].

\section{Conclusions}

Clinical and radiological outcomes of ACDF with TTNor PEEK-cages do not appear to be influenced by the chosen synthetic graft. The occurrence of cage subsidence cannot be solely related to the cage material and its modulus of elasticity, which represents only one of many physical properties of a graft. Design, shape, size, surface architecture of a cage as well as bone density, endplate preparation and applied distraction during surgery need to be considered as further important factors.

Both grafts have certain advantages and should maintain their place in spine surgery. A multifactorial genesis of cage subsidence needs to be considered and further investigated, preferably in a prospective randomized study setting.

\section{Abbreviations}

ACDF: anterior cervical discectomy and fusion; ASD: adjacent segment disease; CT: computer tomography; DDD: degenerative disc disease
MRI: magnetic resonance imaging; NDI: neck disability index; PEEK: polyetheretherketone; ROM: range of motion; SEM: standard error of the mean; TTN: titanium; VAS: visual analogue scale.

\section{Competing interests}

Dr. Stefan Kroppenstedt is a consultant for B Braun Aesculap.

\section{Authors' contributions}

MC was responsible for conception, design, data analysis, writing and editing of the MS. SÖ DK was responsible for data analysis, writing and editing of the MS, DK was responsible for data analysis and editing of the MS, SK was responsible for conception, design, data analysis and editing of the MS. "All authors read and approved the final manuscript."

\section{Acknowledgements}

We thank Mrs. Leah Hecker for editing the manuscript.

Received: 23 April 2012 Accepted: 7 September 2012

Published: 14 September 2012

\section{References}

1. Dorai Z, Morgan H, Coimbra C: Titanium cage reconstruction after cervical corpectomy. J Neurosurg 2003, 99(1 Suppl):3-7.

2. Hacker RJ: A randomized prospective study of an anterior cervical interbody fusion device with a minimum of 2 years of follow-up results. J Neurosurg 2000, 93(2 Suppl):222-226.

3. Mastronardi L, Ducati A, Ferrante L: Anterior cervical fusion with polyetheretherketone (PEEK) cages in the treatment of degenerative disc disease. Preliminary observations in 36 consecutive cases with a minimum 12-month follow-up. Acta Neurochir (Wien) 2006, 148(3):307-312. discussion 312

4. Vadapalli S, Sairyo K, Goel VK, Robon M, Biyani A, Khandha A, Ebraheim NA Biomechanical rationale for using polyetheretherketone (PEEK) spacers for lumbar interbody fusion-A finite element study. Spine (Phila Pa 1976) 2006, 31(26):E992-E998.

5. Hacker RJ, Cauthen JC, Gilbert TJ, Griffith SL: A prospective randomized multicenter clinical evaluation of an anterior cervical fusion cage. Spine (Phila Pa 1976) 2000, 25(20):2646-2654. discussion 2655

6. Profeta G, de Falco R, lanniciello G, Profeta L, Cigliano A, Raja Al: Preliminary experience with anterior cervical microdiscectomy and interbody titanium cage fusion (Novus CT-Ti) in patients with cervical disc disease. Surg Neurol 2000, 53(5):417-426.

7. Cabraja M, Kroppenstedt S: Bone grafting and substitutes in spine surgery. J Neurosurg Sci 2012, 56(2):87-95.

8. McKenna PJ, Freeman BJ, Mulholland RC, Grevitt MP, Webb JK, Mehdian SH: A prospective, randomised controlled trial of femoral ring allograft versus a titanium cage in circumferential lumbar spinal fusion with minimum 2-year clinical results. Eur Spine J 2005, 14(8):727-737.

9. Johansson CB, Roser K, Bolind P, Donath K, Albrektsson T: Bone-tissue formation and integration of titanium implants: an evaluation with newly developed enzyme and immunohistochemical techniques. Clin Implant Dent Relat Res 1999, 1(1):33-40.

10. Schmieder K, Wolzik-Grossmann M, Pechlivanis I, Engelhardt M, Scholz M, Harders A: Subsidence of the wing titanium cage after anterior cervical interbody fusion: 2-year follow-up study. J Neurosurg Spine 2006, 4(6):447-453.

11. Cabraja M, Abbushi A, Kroppenstedt S, Woiciechowsky C: Cages with fixation wings versus cages plus plating for cervical reconstruction after corpectomy - is there any difference? Cen Eur Neurosurg 2011, 71(2):59-63.

12. Cabraja M, Abbushi A, Koeppen D, Kroppenstedt S, Woiciechowsky C: Comparison between anterior and posterior decompression with instrumentation for cervical spondylotic myelopathy: sagittal alignment and clinical outcome. Neurosurg Focus 2010, 28(3):E15.

13. Thome C, Krauss JK, Zevgaridis D: A prospective clinical comparison of rectangular titanium cages and iliac crest autografts in anterior cervical discectomy and fusion. Neurosurg Rev 2004, 27(1):34-41.

14. Brantigan JW, Steffee AD, Lewis ML, Quinn LM, Persenaire JM: Lumbar interbody fusion using the Brantigan $\mathrm{I} / \mathrm{F}$ cage for posterior lumbar interbody fusion and the variable pedicle screw placement system: twoyear results from a Food and Drug Administration investigational device exemption clinical trial. Spine (Phila Pa 1976) 2000, 25(11):1437-1446. 
15. Cutler AR, Siddiqui S, Mohan AL, Hillard VH, Cerabona F, Das K: Comparison of polyetheretherketone cages with femoral cortical bone allograft as a single-piece interbody spacer in transforaminal lumbar interbody fusion. J Neurosurg Spine 2006, 5(6):534-539.

16. Chou YC, Chen DC, Hsieh WA, Chen WF, Yen PS, Harnod T, Chiou TL, Chang YL, Su CF, Lin SZ, et al: Efficacy of anterior cervical fusion: comparison of titanium cages, polyetheretherketone (PEEK) cages and autogenous bone grafts. J Clin Neurosci 2008, 15(11):1240-1245.

17. Meier U, Kemmesies D: [Experiences with six different intervertebral disc spacers for spondylodesis of the cervical spine]. Orthopade 2004 , 33(11):1290-1299.

18. Niu CC, Liao JC, Chen WJ, Chen LH: Outcomes of interbody fusion cages used in 1 and 2-levels anterior cervical discectomy and fusion: titanium cages versus polyetheretherketone (PEEK) cages. J Spinal Disord Tech 2012, 23(5):310-316.

19. Matge $\mathrm{G}$ : Cervical cage fusion with 5 different implants: 250 cases. Acta Neurochir (Wien) 2002, 144(6):539-549. discussion 550.

20. Barsa $P$, Suchomel $P$ : Factors affecting sagittal malalignment due to cage subsidence in standalone cage assisted anterior cervical fusion. Eur Spine J 2007, 16(9):1395-1400.

21. Chiang CJ, Kuo YJ, Chiang YF, Rau G, Tsuang YH: Anterior cervical fusion using a polyetheretherketone cage containing a bovine xenograftp: three to five-year follow-up. Spine (Phila Pa 1976) 2008, 33(23):2524-2428.

22. Francke El, Demetropoulos CK, Agabegi SS, Truumees E, Herkowitz HN: Distractive force relative to initial graft compression in an in vivo anterior cervical discectomy and fusion model. Spine (Phila Pa 1976) 2010, 35(5):526-530

23. Yang JJ, Yu CH, Chang BS, Yeom JS, Lee JH, Lee CK: Subsidence and nonunion after anterior cervical interbody fusion using a stand-alone polyetheretherketone (PEEK) cage. Clin Orthop Surg 2011, 3(1):16-23.

24. Lemcke J, Al-Zain F, Meier U, Suess O: Polyetheretherketone (PEEK) Spacers for Anterior Cervical Fusion: A Retrospective Comparative Effectiveness Clinical Trial. Open Orthop J 2011, 5:348-353.

25. Cabraja M, Klein M, Lehmann TN: Long-term results following titanium cranioplasty of large skull defects. Neurosurg Focus 2009, 26(6):E10.

26. Verran J, Whitehead K: Factors affecting microbial adhesion to stainless steel and other materials used in medical devices. Int J Artif Organs 2005, 28(11):1138-1145.

27. Diedrich O, Perlick L, Schmitt O, Kraft CN: Radiographic characteristics on conventional radiographs after posterior lumbar interbody fusion: comparative study between radiotranslucent and radiopaque cages. $J$ Spinal Disord 2001, 14(6):522-532

28. Disch AC, Schaser KD, Melcher I, Feraboli F, Schmoelz W, Druschel C, Luzzati A: Oncosurgical results of multilevel thoracolumbar en-bloc spondylectomy and reconstruction with a carbon composite vertebral body replacement system. Spine (Phila Pa 1976) 2011, 36(10)):E647-E655.

29. Teo EC, Yang K, Fuss FK, Lee KK, Qiu TX, Ng HW: Effects of cervical cages on load distribution of cancellous core: a finite element analysis. J Spinal Disord Tech 2004, 17(3):226-231.

30. Wilke HJ, Kettler A, Goetz C, Claes L: Subsidence resulting from simulated postoperative neck movements: an in vitro investigation with a new cervical fusion cage. Spine (Phila Pa 1976) 2000, 25(21):2762-2770.

31. Pechlivanis I, Thuring T, Brenke C, Seiz M, Thome C, Barth M, Harders A, Schmieder K: Non-fusion rates in anterior cervical discectomy and implantation of empty polyetheretherketone cages. Spine (Phila Pa 1976) 2011, 36(1):15-20

32. Tureyen $\mathrm{K}$ : Disc height loss after anterior cervical microdiscectomy with titanium intervertebral cage fusion. Acta Neurochir (Wien) 2003, 145(7):565-569. discussion 569-570.

33. Cabraja M, Koeppen D, Lanksch WR, Maier-Hauff K, Kroppenstedt S: Polymethylmethacrylate-assisted ventral discectomy: rate of pseudarthrosis and clinical outcome with a minimum follow-up of 5 years. BMC Musculoskelet Disord 2011, 12:140.

34. Andaluz N, Zuccarello M, Kuntz C: Long-term follow-up of cervical radiographic sagittal spinal alignment after 1- and 2-level cervical corpectomy for the treatment of spondylosis of the subaxial cervical spine causing radiculomyelopathy or myelopathy: a retrospective study. J Neurosurg Spine 2012, 16(1):2-7.

35. Harrison DD, Janik TJ, Troyanovich SJ, Holland B: Comparisons of lordotic cervical spine curvatures to a theoretical ideal model of the static sagittal cervical spine. Spine (Phila Pa 1976) 1996, 21(6):667-675.
36. Kulkarni AG, Hee HT, Wong HK: Solis cage (PEEK) for anterior cervical fusion: preliminary radiological results with emphasis on fusion and subsidence. Spine J 2007, 7(2):205-209.

37. Boker DK, Schultheiss R, Probst EM: Radiologic long-term results after cervical vertebral interbody fusion with polymethyl methacrylat (PMMA). Neurosurg Rev 1989, 12(3):217-221.

38. Barlocher CB, Barth A, Krauss JK, Binggeli R, Seiler RW: Comparative evaluation of microdiscectomy only, autograft fusion, polymethylmethacrylate interposition, and threaded titanium cage fusion for treatment of single-level cervical disc disease: a prospective randomized study in 125 patients. Neurosurg Focus 2002, 12(1):E4.

39. van den Bent MJ, Oosting J, Wouda EJ, van Acker RE, Ansink BJ, Braakman R: Anterior cervical discectomy with or without fusion with acrylate. A randomized trial. Spine (Phila Pa 1976) 1996, 21(7):834-839. discussion 840.

40. Brown JA, Havel P, Ebraheim N, Greenblatt SH, Jackson WT: Cervical stabilization by plate and bone fusion. Spine (Phila Pa 1976) 1988, 13(3):236-240.

41. Gassman J, Seligson D: The anterior cervical plate. Spine (Phila Pa 1976) 1983, 8(7):700-707.

42. Kaiser MG, Haid RW Jr, Subach BR, Barnes B, Rodts GE Jr: Anterior cervical plating enhances arthrodesis after discectomy and fusion with cortical allograft. Neurosurgery 2002, 50(2):229-236. discussion 236-228.

43. Wang JC, McDonough PW, Endow KK, Delamarter RB: Increased fusion rates with cervical plating for two-level anterior cervical discectomy and fusion. Spine (Phila Pa 1976) 2000, 25(1):41-45.

44. Samartzis D, Shen FH, Lyon C, Phillips M, Goldberg EJ, An HS: Does rigid instrumentation increase the fusion rate in one-level anterior cervical discectomy and fusion? Spine J 2004, 4(6):636-643.

45. Jagannathan J, Shaffrey Cl, Oskouian RJ, Dumont AS, Herrold C, Sansur CA, Jane JA: Radiographic and clinical outcomes following single-level anterior cervical discectomy and allograft fusion without plate placement or cervical collar. J Neurosurg Spine 2008, 8(5):420-428.

doi:10.1186/1471-2474-13-172

Cite this article as: Cabraja et al:: Anterior cervical discectomy and fusion: Comparison of titanium and polyetheretherketone cages. BMC Musculoskeletal Disorders 2012 13:172.

\section{Submit your next manuscript to BioMed Central and take full advantage of:}

- Convenient online submission

- Thorough peer review

- No space constraints or color figure charges

- Immediate publication on acceptance

- Inclusion in PubMed, CAS, Scopus and Google Scholar

- Research which is freely available for redistribution 